\title{
Methodological Foundations for Teaching Computer Graphics for Students in IT Areas
}

\author{
Vitaly Karabchevsky \\ Donetsk National Technical University, 58 Artyom Street, Donetsk, 83001, Ukraine \\ karabchevski@mail.ru
}

\begin{abstract}
Computer technologies of graphic education of students studying programming and information technologies are considered. Particular attention is paid to the joint use of descriptive geometry methods and three-dimensional geometric modeling tools in the creation and study of models of geometric shapes. A basic set of competencies has been identified, allowing to solve the main types of computer graphics tasks, methods for achieving these competencies are considered.
\end{abstract}

Keywords: Descriptive Geometry, Computer Graphics, AutoCAD, Three-Dimensional Geometric Modeling, Development of Graphic Systems.

\section{Introduction}

Traditionally, graphic preparation was carried out and is being carried out for students of construction, engineering and other engineering specialties. In the 70s of the last century in a university that was known in the USSR under the name "Donetsk Polytechnic Institute" (DPI), descriptive geometry and engineering graphics were read even for the specialty "Applied Mathematics". In the years 80-90, electricians, automation specialists, circuit designers, computer hardware specialists tried to reduce the full graphic preparation of their students, agreeing only with the need to study the rules for designing electrical and other circuits. What can be said about programmers! It seemed possible to study the rules for designing flowcharts of algorithms without studying a special graphic discipline. The course program "Dialogue Systems and Computer Graphics" focused on the development of a graphical interface.

Contrary to the above, in DPI in the late 70s - early 80s there was an interest in the computer-aided generation of drawings and images. Initially, these technologies were mastered at the computer center and departments of the faculty of computer technology. The level of work can be judged by the fact that one of the first flight simulators in the USSR was designed and partially made in Donetsk by teachers and staff of this faculty.

In the early 90s, a group of experts and lovers of computer graphics gathered at the department of applied mathematics and computer science. Therefore, in the course

Copyright (C) 2020 for this paper by its authors. Use permitted under Creative Commons License Attribution 4.0 International (CC BY 4.0). 
"Engineering Graphics" (later "Engineering and Computer Graphics") for students of the specialty "Software", whose program included descriptive geometry, AutoCAD became the tool for laboratory work. Even at the initial stage, this method of completing assignments could not be called "drawing on the screen," since the students used the means of precise constructions (object snaps).

\section{The Development of Communications between Two- dimensional and Three-dimensional Models}

\subsection{Learning Main Geometric Objects}

The desire to strengthen the understanding of the relationships between two-dimensional and three-dimensional models of objects has led to the development of software and methodological tools to support such a relationship, intended both for use in lecturing and for students works (Fig. 1) [1]. Subsequently, a computer textbook (Fig. 2) [2], testing tools [3], a set of static and dynamic slides designed for lectures were developed. To maintain the relationship between $2 \mathrm{D}$ and $3 \mathrm{D}$ models of bodies and surfaces, AutoCAD is mainly used now. At the same time, those tasks for which threedimensional modeling tools exist are solved both by traditional methods of descriptive geometry and using 3D models. Here are some examples.

You can lower the perpendicular to the plane both in the traditional way and using a three-dimensional model of a point and a triangle (Fig. 3) [4]. The dihedral angle can be found by bringing its edge to the projecting position by replacing the planes. Having built a 3D model of the dihedral angle, you can go to the coordinate system whose $\mathrm{z}$ axis is directed along its edge and measure the desired angle (Fig. 4) [4].

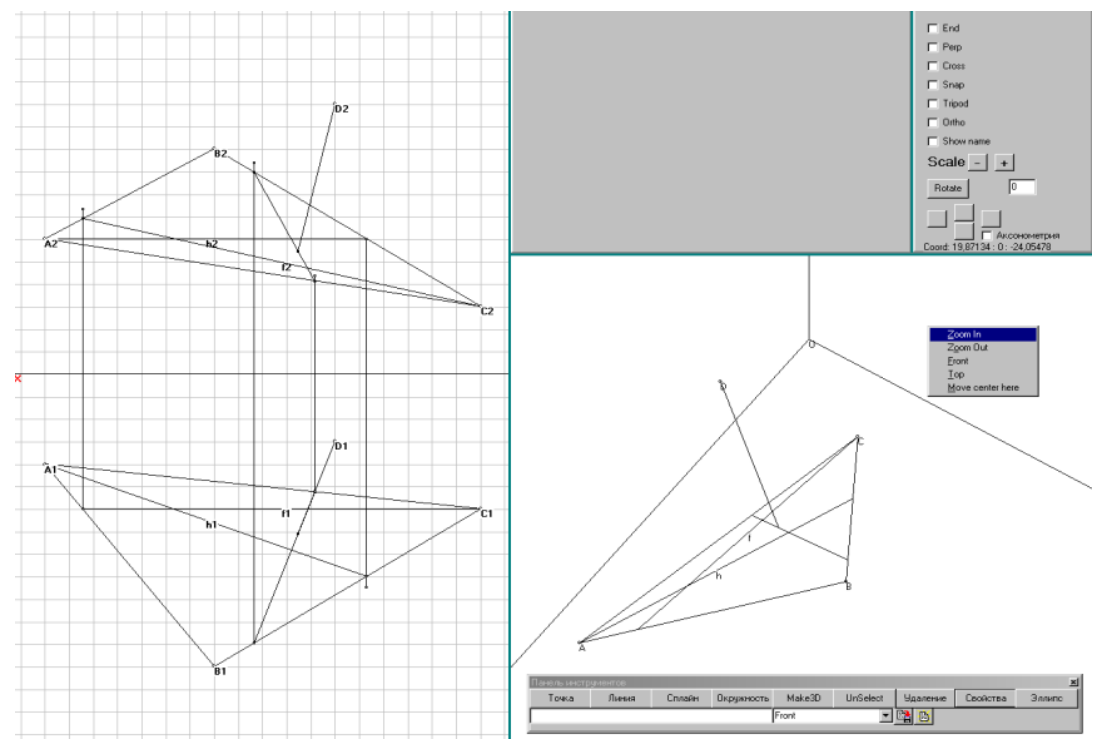

Fig. 1. Perpendicular to the plane 


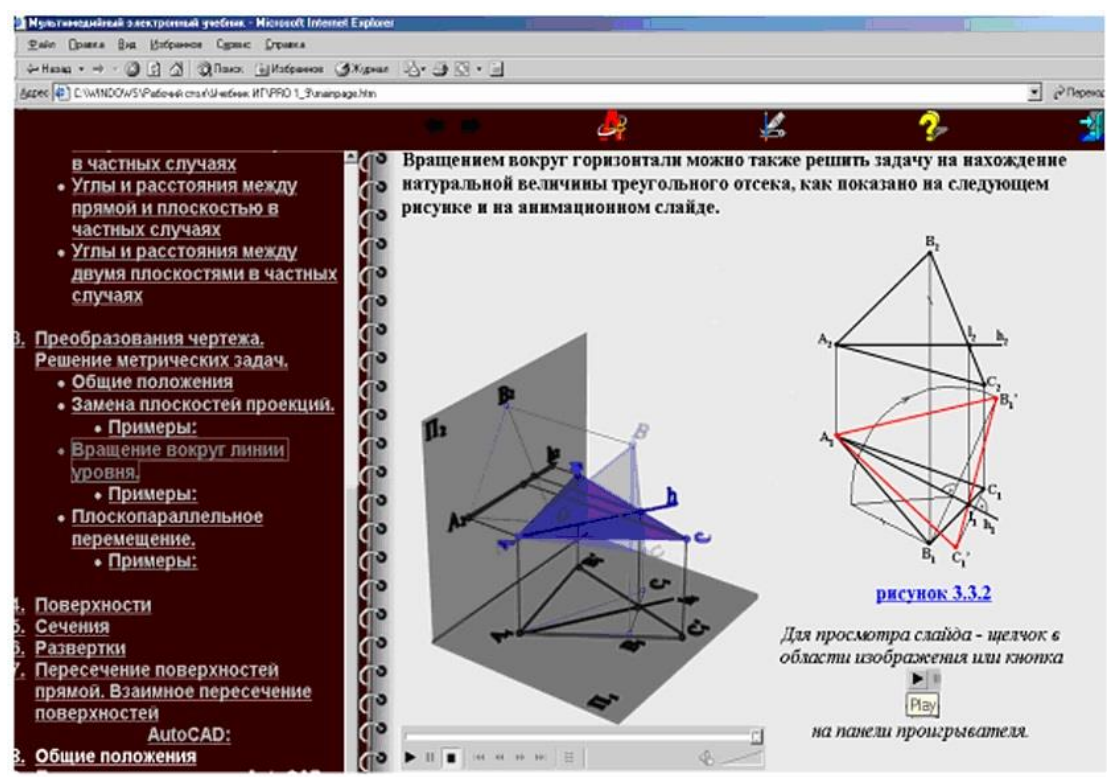

Fig. 2. Computer textbook

To determine the distance between the skew lines, you can build a line passing through an arbitrary point of one of the lines and parallel to the other line. Having lowered the perpendicular from an arbitrary point of another straight line to the plane defined by the intersecting straight lines and finding the point of intersection of the perpendicular with the plane, we obtain a segment whose length is the desired distance (Fig. 5). This method is more visual than the reduction of one of the straight lines to the projection position, which is traditionally used in descriptive geometry, for which, in the general case, two plane changes are needed.

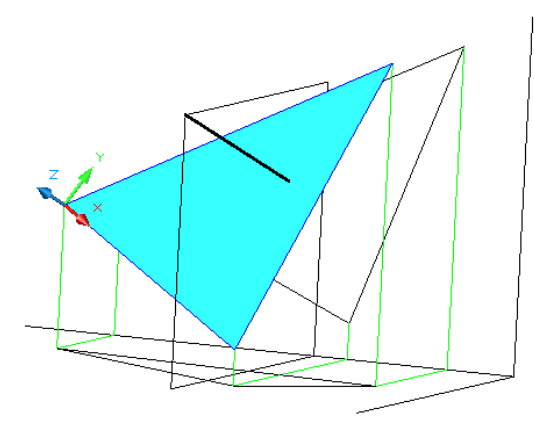

Fig. 3. Building a perpendicular to the plane of the triangle

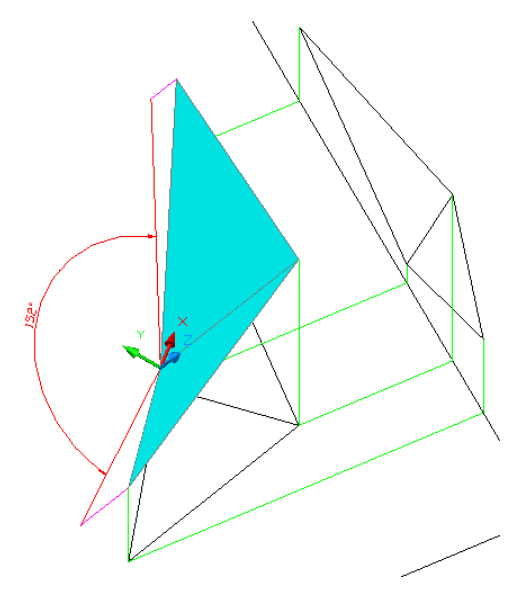

Fig. 4. Finding the value of the dihedral angle 

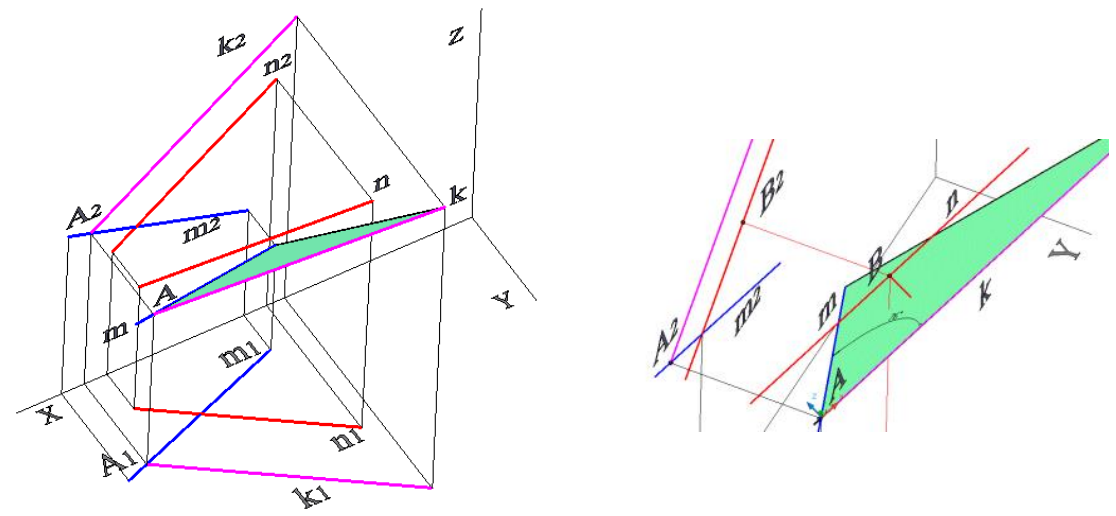

Fig. 5. The distance between the skew lines

\subsection{Study of Solids and Surfaces}

In the study of polyhedra and curved surfaces, the use of 3D modeling tools is effective [5]. If the figure can be represented by the surface of a solid-state object, its plane section can be obtained using the SECTION command, comparing Figures 6 and 7, you can verify the usefulness of using these tools.

When finding the points of intersection of a line and a surface in this way, you can find an auxiliary section (Fig. 8). The intersection lines of surfaces can also be extracted from solid models of intersecting objects [6] (Fig. 9).

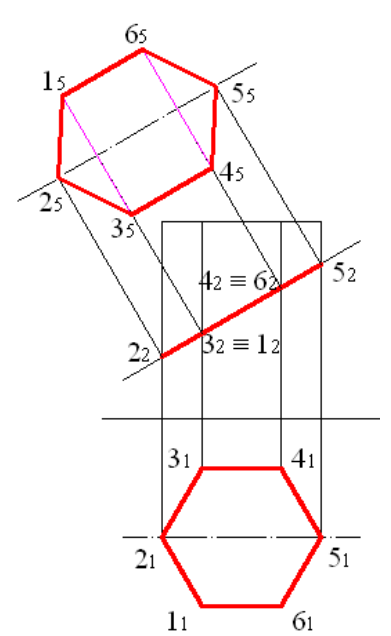

Fig. 6. The cross section of the prism

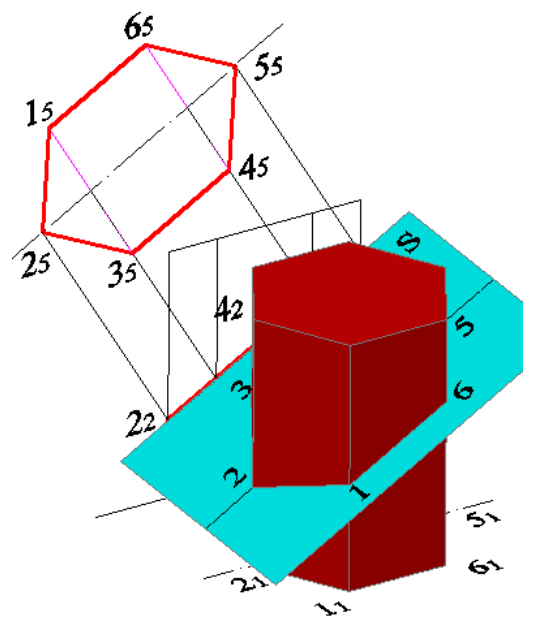

Fig. 7. Three-dimensional model of the section 
If the studied geometric object cannot be represented by the surface of a solid, surface modeling tools are used to study it (Fig. 10) [6].

The mentioned methods and tools are applied in the course, which is now called "Computer Graphics" and is read by the author for some areas of the enlarged groups 09.00.00 and 02.00.00 (already new standards). For those who are used to the terminology that is traditional for computer science, the name of the course is discordant with its content, and the author would prefer the name "Computer Geometry Tools", but some features of the curriculum still do not allow renaming the subject.

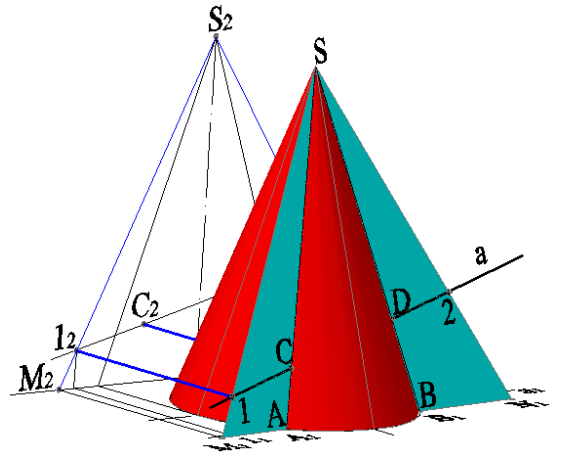

Fig. 8. Three-dimensional model of finding intersection points

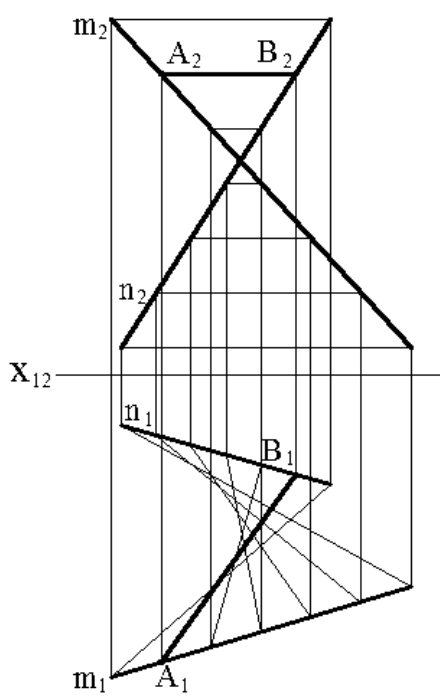

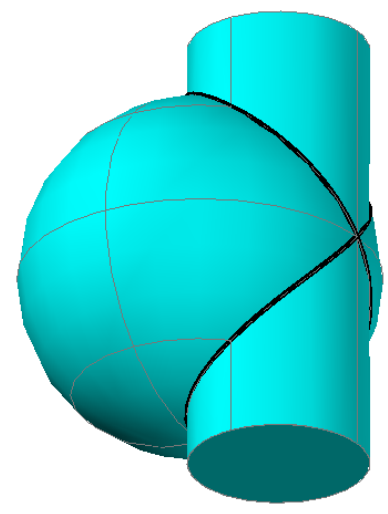

Fig. 9. The line of intersection of the surfaces

Fig. 10. Modeling a hyperbolic paraboloid with a three-dimensional mesh 


\section{The Competencies Necessary for Solving Computer Graphics Tasks}

Of course, the course under consideration is only the beginning of the study of computer graphics in the broad sense of the word.

Students of the direction 09.03.02 "Information Systems and Technologies" of the profile "Information Technologies in the Media Industry and Design" study the course "Geometric Modeling", where they study the corresponding algorithms and tools, as well as programming in the AutoCAD environment. Course work is carried out, consisting in the development of a program that forms a solid-state model of an object defined by a visual image, the sizes are variable (Fig. 11.).

The subject "Computer geometry and geometric modeling", which is close in content, is studied by students of the 02.03.01 direction "Mathematics and Computer Science".

For the direction 09.03.04 "Software Engineering", the author reads the course "Architecture and Design of Graphic Systems". During the course design, a graphic editor is developed, which should generate, view and edit models of three-dimensional objects (Fig. 12). Various programming languages and graphic libraries are used.
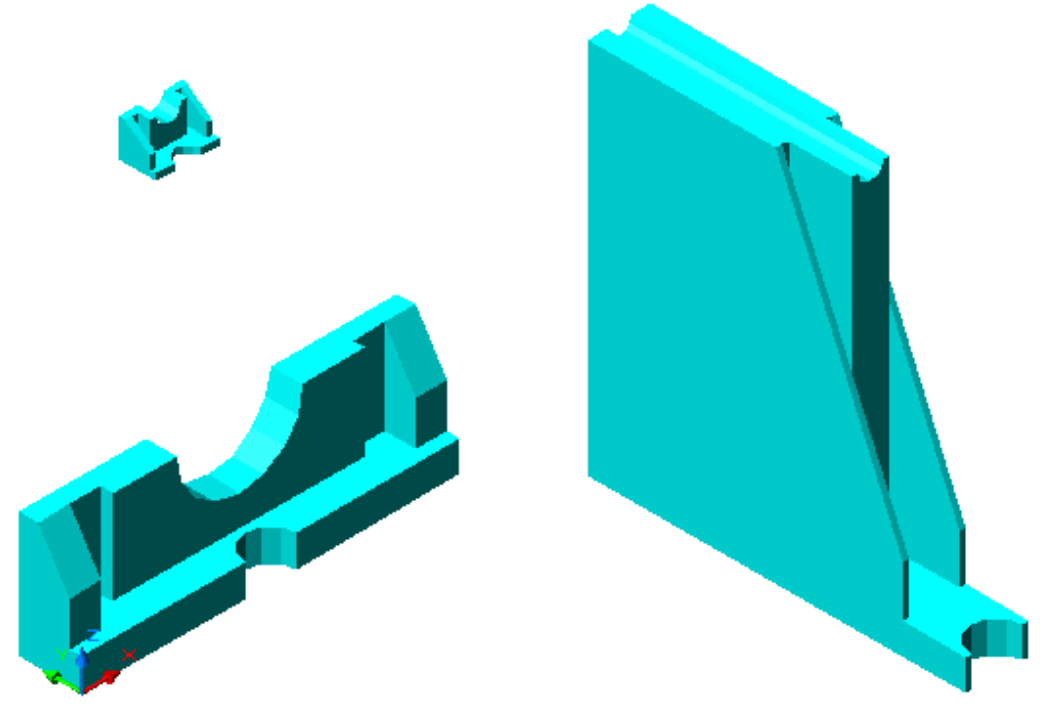

Fig. 11. Parameterized solid model obtained using AutoLISP

The competencies mastered during the study of the above courses consist in the ability to use two-dimensional and three-dimensional geometric models for modeling and designing objects and processes, to develop computer graphics software. They are the basis for studying such subjects as "Computer Graphics and Advertising", "Industrial Design", "Three-Dimensional Modeling and Animation", "Design of Advertising Calls", "Virtual Reality Systems", as well as for students' scientific work. 


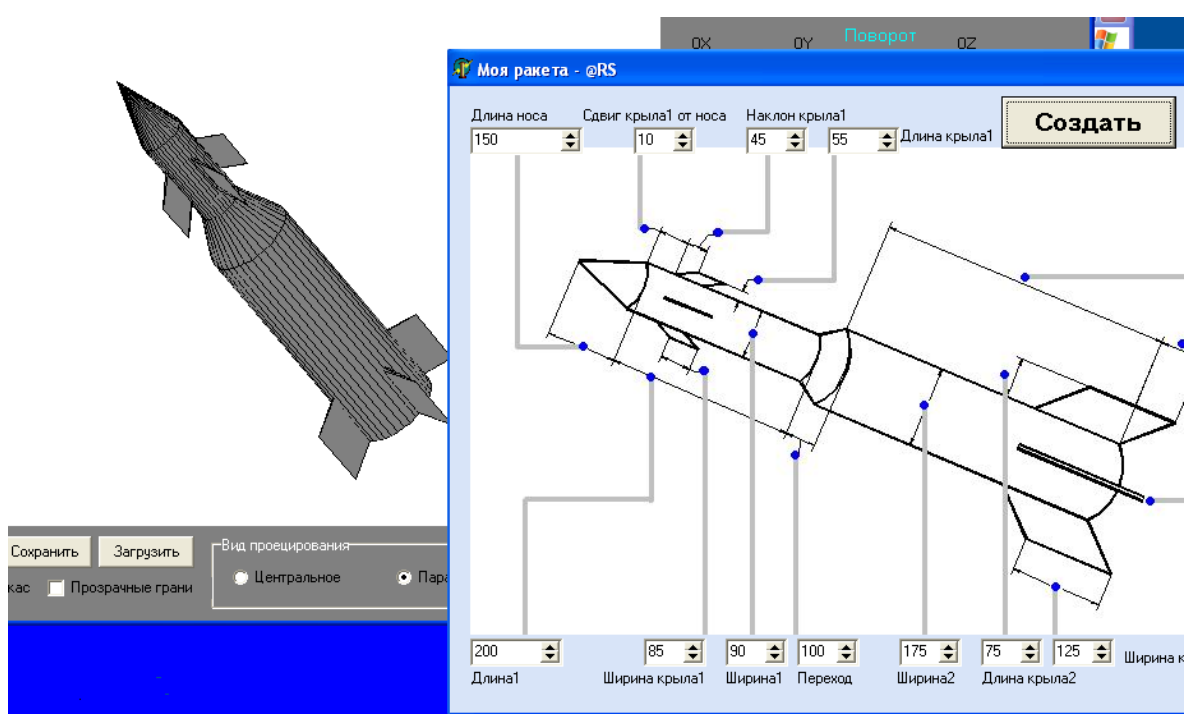

Fig. 12. The editor of polygonal models

\section{Conclusion}

According to the author, this approach to the graphic preparation of IT students has provided them with qualifications that meet modern requirements, allowing them to work as developers and users of graphic systems, which strengthens their position in the labor market.

The recommendations followed in many higher education institutions [7] limit the study of computer graphics to the design of an interface and computer animation, which does not correspond to the position it occupies in the field of computer science.

\section{References}

1. Karabchevsky V. Improving the quality of teaching engineering graphics through the development and application of training systems. // Scientific works of Donetsk State Technical University. Series: Informatics, Cybernetics and Computing, (IKVT-99). - Issue 6 - Donetsk: DonSTU, 1999. - pp. 294-299.

2. Karabchevsky V. Multimedia textbook on descriptive geometry // Education and Virtuality2002. Collection of scientific papers of the 6th International Conference of the Ukrainian Association for Distance Education. Kharkiv-Yalta: UADO. - 2002. - pp. 198-203.

3. Karabchevsky V. Automatic generation of the descriptive geometry tasks solving as a means of the standard formation in the testing subsystem // Scientific papers of Donetsk National Technical University. Series "Problems of modeling and automation of dynamic systems design" (MAP - 2002). Issue 52. Donetsk: DonNTU. - 2002. - pp. 94 - 99. 
8 V. Karabchevsky

4. Karabchevsky V. Three-dimensional modeling and descriptive geometry in the course "Methods of computer geometry" // Interdepartmental scientific and technical collection "Technical aesthetics and design". Issue 8. - Kyiv: KNUBA, 2011 - pp. 138-142.

5. Karabchevsky V. Computer technologies of teaching graphic disciplines for the specialists in software development // Interdepartmental scientific and technical collection "Technical aesthetics and design". - Kyiv: KNUBA, 2012, № 89. - pp. 171-174.

6. Karabchevsky V. Methods of computer geometry. - Donetsk: GVUZ "DonNTU”, Technopark DonNTU "UNITECH”, 2010. - 179 p.

7. Recommendations for teaching software engineering and computer science at universities: Tr. from English - M.: INTUIT.RU "Internet University of Information Technologies", 2007. $-462 \mathrm{p}$. 